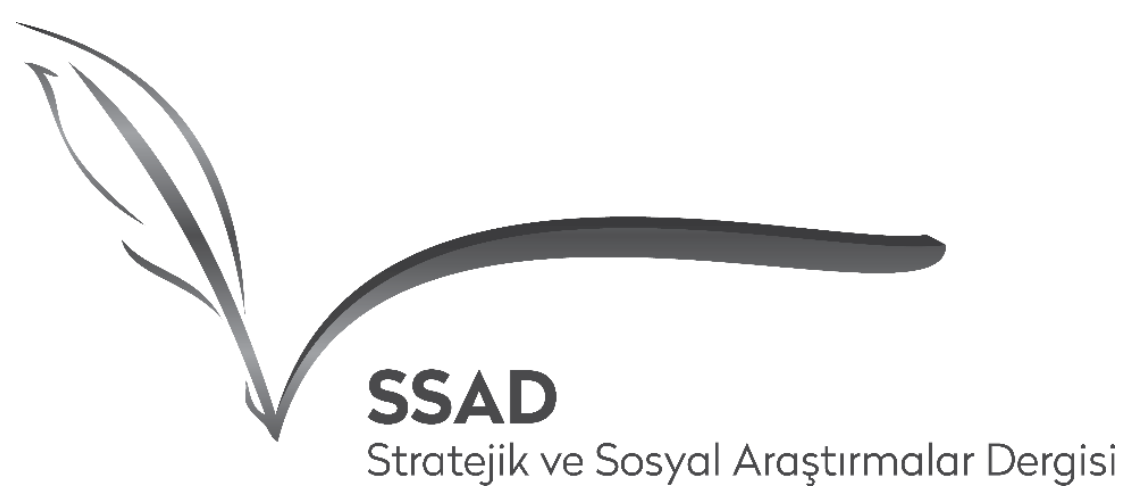

ISSN: 2587-2621

Volume 2 Issue 2, July 2018

\title{
GÜNCEL TASARIM UYGULAMALARINDA YENI BİR PARADİGMA: OYUNLAŞTIRMA
}

\author{
A New Paradigm In Current Design Applications: Ganification
}

\author{
Salih AKKEMİ*
}

Öz: Son yıllarda daha sık duymaya başladığımız Oyunlaştırma (gamification) kavramı iş dünyası başta olmak üzere eğitim ve çok sayıda görsel tasarım disiplinine ait uygulamalarda karşımıza çıkmaya devam etmektedir. Farklı uygulama alanlarında kullanılan bu anlayışa göre insanların genel tutum ve davranışlarını değiştirerek problem çözmeye yönelik daha eğlenceli uygulamaların tasarlanmasına çalışılmaktadır. Bir motivasyon aracı olarak da kullanılan oyunlaştırma, oyun dünyasına ait belirli dinamikleri ve özellikleri oyun dünyasına ait olmayan oyun dışı alanlarda kullanımı üzerine odaklanır. Mobil cihazlar, İnternet ve sosyal medyanın da desteğiyle insanların oyun tabanlı uygulamaları günlük hayatları içinde kullanmalarını arttıracak oyunlaştırmanın kullanım fırsatlarını fazlalaştırmaktadır. Bu faktörlerden mobil cihazların günlük hayat içinde kullanıcı açısından vazgeçilmez bir nesne haline gelmesi ve mobil uygulamaların öneminin giderek artması da oyunlaştırma kullanım pratiklerinin artmasına yardımcı olmaktadır. Başta görsel tasarım alanları olmak üzere çok geniş çerçevede ele alınabilecek güncel tasarım uygulamaları, oyunlaştırmanın kullanımı açısından yeni ve farklı alanlar oluşturmaktadır. Bu uygulamalar içinde pazarlama çalışmaları, reklam ve tanıtım faaliyetleri, e-ticaret uygulamaları, sosyal medya uygulamaları veya farklı paylaşım platformları, sosyal sorumluluk projeleri, web veya mobil uygulamalar gibi çok sayıda uygulama alanı oyunlaştırmanın kullanımı açısından ele alınabilir. Kullanıcı sayısını artırmak, insanları istenen aksiyona teşvik etmek, motivasyonu arttırmak ve satış rakamlarını arttırmak gibi farklı hedefler için oyunlaştırma çalışmalarından yararlanılmaktadır. Bu çalışmalar kapsamında derecelendirme, rekabet ve ödüllendirme sistemleri gibi oyunlaştırmanın temel özelliklerini yukarıda belirtilen tasarım çalışmalarında sıklıkla görülmektedir. Bu çalışmada oyunlaştırmanın genel çerçevesi ortaya konarak oyunlaştırmayı oluşturan temel özellikler yeni bir paradigma olarak güncel tasarım uygulamalarında incelenmiştir. Çalışma kapsamında güncel tasarım uygulamaları açısından oyunlaştırmanın yeri, önemi ve geleceği ile ilgili değerlendirmelere yer verilmiştir.

Anahtar Kelimler: Oyunlaştırma, tasarım, güncel tasarım uygulamaları.

\begin{abstract}
In recent years, we see that the concept of gamification is used in education, especially in the business world, and in the applications of many visual design disciplines. Gamification is aimed at more fun applications for problem solving by changing general attitudes and behaviors of people. Gamification, also used as a motivation tool, focuses on the use of certain dynamics and characteristics of the game world in non-gaming areas that are not in the game world. Current design applications that can be considered in a wide range of fields, especially visual design fields, create new and different fields in terms of the use of gamification. Gamification involves marketing, advertising and promotional
\end{abstract}

\footnotetext{
* Öğr.Gör., Mimar Sinan Güzel Sanatlar Üniversitesi, Enformatik Bölümü salih.akkemik@ msgsu.edu.tr
} 
activities, e-commerce applications, social media applications, social responsibility projects, the Web or a large number of applications. It is used for different purposes such as increasing the number of users, encouraging people to desired action, increasing motivation and increasing sales figures. The basic components of gamification that includes rating, competition and rewarding systems frequently appear in the design studies of these areas. In this paper, the general framework of gamification is introduced and the main elements of gamification are examined in current design applications as a new paradigm. In the scope of this study, the place of gamification, the importance and the future of the gamification in terms of current design applications are investigated. Keywords: Gamification, design, current design applications.

\section{Giriş}

İnsanların doğduğu andan itibaren oyun kavramı ile birlikte yaşamaya başlamaktadır ve hayatın farklı zaman ve durumlarında devam etmektedir. Eğlence faktörü üzerine temellenen oyun kavramı, günümüzde sadece çocukların düzenli bir aktivitesi değildir ve eğlenme ihtiyacı duyulan zamanların dışına da çıkarak çok büyük bir alana yayılmıştır. Bu alan aynı zamanda çok fazla sayıda disiplinin çalışma ve araştırma kapsamına girmiştir. Gelişen teknoloji ve iletişim kanallarıyla farklı bir boyuta ulaşan oyunlar, günümüzde sosyal yaşam içinde kendine vazgeçilmez bir yer edinmiştir. Bu çerçevede iş dünyasından eğitime kadar pek çok alanda oyunların sağladığı olumlu etkilerden faydalanılması normal bir sonuç olarak görülmektedir. Günümüz yaşam koşulları ile zamandan ve mekandan bağımsız olarak insanların oyun oynama eğilimleri, başta pazarlama ve öğrenme yollarını geleneksel yöntemlerden farklı yönlere geliştirilmesi adına kullanılmaya çalışılmaktadır. Oyun dünyası dışında ele alınan bu durum oyunlaştırma (gamification) ismiyle karşımıza çıkmaktadır. Bu yaklaşım günümüz tasarım uygulamalarında ele alınarak gerçekleştirilen çalışmalarda oyunlaştırmayı oluşturan temel özelliklerden faydalanılmaktadır.

$\mathrm{Bu}$ çalışmanın devamında tasarım kavramı ve güncel görsel tasarım alanı açıklanmış, oyunlaştırmanın tanımı ve özellikleri incelenmiş, sıklıkla kullanıldığı tasarım uygulamaları açısından ele alınarak değerlendirilmiştir. Asıl belirtilmek istenen noktalar olarak da oyunlaştırmanın güncel tasarım uygulamalarına katkıları olarak açıklanmıştır.

\section{Tasarım Kavramı}

Tasarım kavramının sözlük anlamına bakıldığında yaratma ve plan yapmak ${ }^{1}$ ile zihinde canlandırılan biçim, tasavvur, bir ürünün ilk taslağı, tasar çizim ve bir araştırma sürecinin çeşitli dönemlerinde izlenecek yol ve işlemleri tasarlayan çerçeve olarak tanımlanmaktadır. ${ }^{2}$ Tasarım sözcüğü, Latince kökenli “designare” kelimesinden gelmektedir ve göstermek ile belirtmek anlamına geldiği gibi çizmek olarak karşılık bulmaktadır. Yaygın kullanımı olan İngilizce "design" sözcügüü bu iki anlamı da barındırmaktadır. ${ }^{3}$ Tasarım aynı zamanda nesnelerin, süreçlerin, hizmetlerin ve bunlara bağlı çok yönlü niteliklerin yaşam döngüleri içerisine yerleştirilmesini amaçlayan yaratıcı bir faaliyet olarak da tanımlanmaktadır. ${ }^{4}$ Bu noktada tasarım, tasarımcının genellikle bir sebeple ortaya çıkan kullanıcı gereksinimlerini karşılamak amacıyla yaratıcı bir süreç içinde ürettiği çözümler olarak da açıklanabilir. ${ }^{5}$ Yaratıcı süreç içinde birbirlerine bağımlı olarak sırayla devam eden kademeli bir işlem olarak tanımlanabilecek tasarım kavramı, hayal-projelendirme-üretim zincirinin, insan beynindeki algılanma kalıbının bir

\footnotetext{
${ }^{1}$ Merriam - Webster Sözlüğü, http://www.merriam - webster.com/dictionary/design, erişim tarihi: 17.05.2018.

2 TDK (Türk Dil Kurumu) Güncel Türkçe Sözlük, http://www.tdk.org.tr erişim tarihi: 17.05.2018.

${ }^{3}$ Brigitte Borja De Mozota, Tasarım Yönetimi, Mediacat Kitapları, İstanbul 2005, s. 8.

${ }^{4}$ B. B. D. Mozota, T. Y., s. 9.

${ }^{5}$ Gülay Hasdoğan, Tasarım Kavramının Hukuktaki Gelisimi ve Endüstriyel Tasarımların Korunmasına İlişkin Ülkemizdeki Yasal Düzenlemelere Yansımaları, Tasarımda Evrenselleşme - 2. Ulusal Tasarım Kongresi Tasarım Kitab1, İstanbul 13-16 Mart 1996, s. 24.
} 
ifadesidir ve bir nesneye uyarlanmadıkça anlam kazanamaz. ${ }^{6}$ Bu bilgiler 1şığında bakıldığında mimarlıktan grafiğe, endüstri ürünlerinden web teknolojilerine kadar pek çok alanda tasarım kavramından söz etmek mümkündür. Bu çalışmanın odak noktasını oluşturan oyunlaştırma kavramı da bahsedilen alanlarda farklı şekillerde kullanılsa da çalışmanın ilerleyen bölümlerinde oyunlaştırmanın güncel tasarım uygulamaları içinde daha fazla kullanıldığı görsel tasarım uygulamaları alanı açısından değerlendirmek faydalı olacaktır.

Günümüzde iletişim teknolojilerinin ileri seviyelerdeki gelişimleri günlük hayatın teknolojik bir iletişim kanalı içinde devam etmesine sebep olmaktadır. İnternet, bilgisayarlar, sosyal medya ve mobil cihazlar insanların neredeyse günün her anında iletişim halinde kalmalarına olanak sağlayarak farklı türdeki görsel ve işitsel işaretlerle karşılaşmalarına sebep olmaktadır.

Güncel tasarım çalışmaları bahsedilen bu işaretlerin tasarlanması ve kullanımı ile yakından ilgilidir. Bu gibi işaret ve semboller, insanlar tarafindan yaşamları içindeki soyut veya somut her türlü duygu, olay, söz, eylem, durum vb. ifade etmek için kullanılır. ${ }^{7}$ Buna bağlı olarak bir duygunun, bir düşüncenin ya da bir kavramın kelimeler yerine imgeler ve semboller kullanılarak anlatılması görsel iletişim olarak kabul edilebilir. ${ }^{8}$ Genel anlamda iletişimin gönderen ve alıcı arasındaki çift yönlü bir yararlanma süreci ve insanlar arasındaki bilgi alışverişi olarak tanımlanması sebebiyle görsel iletişim için basit bir tanımla görüntülü bilgilerin alışverişidir denilebilir. ${ }^{9}$ Görsel iletişimin geçmiş̧inin ilkel çağlardaki mağara resimlerine kadar uzandığ görülmektedir ve bu noktadan anlaşıldığı üzere insanlar arasında iletişimin en eski ve en doğal formlarından biridir [Şekil 1]. ${ }^{10}$

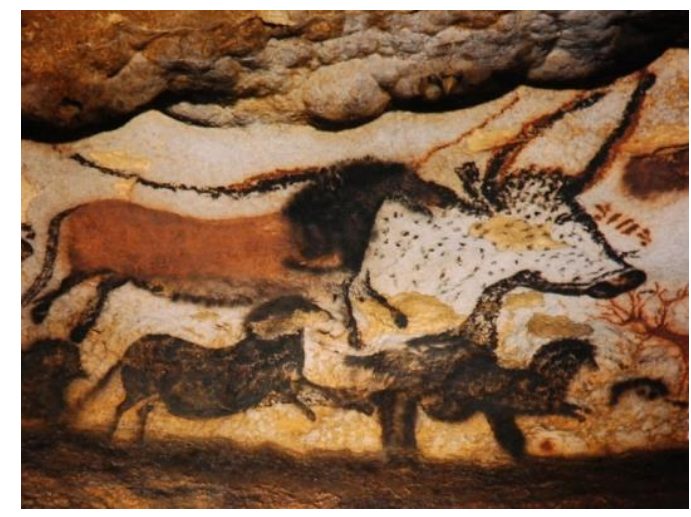

Şekil 1: Lascaux mağara resimleri, Fransa, M.Ö. 15.000 (https://medussa.net/content/files/news/111142669-21-May2017-17-11-43.jpg adresinden alınmıştır. Erişim tarihi 29 Nisan 2018)

$\mathrm{Bu}$ çalışmanın ilerleyen kısımlarında örnek olarak ele alınan güncel görsel tasarım uygulamaları genel hatlarıyla görsel iletişim temelinde değerlendirilebilecek uygulamalardır. Bu sebeple güncel görsel tasarım uygulamalarını değerlendirmeden önce görsel iletişimin genel çerçevesini ele alarak devam etmekte fayda vardır. Yukarıdaki örnekte görüldügü üzere çok eski zamanlardan başlayarak tasarlanmaya çalışılan görsel iletişim temel olarak üç bileşenden oluşur: ${ }^{11}$

- Bir yöntem (tasarım)

- Bir amaç (iletişim)

\footnotetext{
6 Özlem Devrim, “Tasarım Kavramı Üzerine Bir Deneme”, https://trendyazilari.blogspot.com/2002/10/tasarimkavrami-uzerine-bir-deneme.html erişim tarihi: 16.05.2018.

${ }^{7}$ David Fontana, The Secret Language of Symbols, Chronicle Books, San Francisco 1994.

${ }^{8}$ Hale Künüçen ve Kağan Olguntürk, Görsel İletişim Öğelerinin Yeni Bir Medya Dili Olarak Sinemada Yeniden Tasarımı, Proc. Int. Conference on Communication, Media, Technology and Design, , İstanbul Nisan 2014, s. 334-337.

${ }^{9}$ Nesli Tuğban Yaban, Sanat ve Görsel İletişimin Buluşma Noktası: Ekslibris, Proc. Int. Participated Science and Culture Symposium, Batman Nisan 2012, s. 973-984.

${ }^{10}$ Banu İnanç Uyan Dur, "Türk Görsel İletişim Tasarımı Ve Kültürel Değerlerle Bağları”, Uluslararası Sosyal Araştırmalar Dergisi, Sayı:37, 2015, s. 443-453.

${ }^{11}$ Jorge Frascara, Communication Design: Principles, Methods, and Practice, AllworthPress, New York 2004.
} 
- Bir ortam (görüntü/görme)

Genel hatlarıyla alanyazında görsel iletişim tasarımı (visual communication design) ve iletişim tasarımı (communication design) aynı anlamda kullanılmaktadır. Buna karşın detaylı düşünüldüğünde ortaya çıkacak ürün sadece görsel olmayabilir, yani işitmeye, dokunmaya, tatmaya veya koklamaya da hitap edebileceği için iletişim tasarımının görsel iletişim tasarımını kapsayıcı bir üst katman olduğu da kabul edilebilir. ${ }^{12}$ Görsel iletişim tasarımı ile sıklıkla aynı anlamda kullanılan iletişim tasarımının amacı insanların tavır ve davranışları üzerinde etki yaratmaktır. ${ }^{13}$

Alanyazında yer alan tanımları özetlemek gerekirse görsel iletişim, belirlenmiş bir amaç doğrultusunda iletilmek istenen mesajın, belirli bir hedef kitleye ulaşabilmesi için yaratıcı ve anlamlı çözümler bulmak ve bunları uygulamaktır. Bu tanıma göre görsel iletişim tasarımının yaratıcı bir süreç olarak mesaj ve hedef kitle arasındaki en doğru yolun tasarlanması şeklinde de tanımlanabilir [Şekil 2].

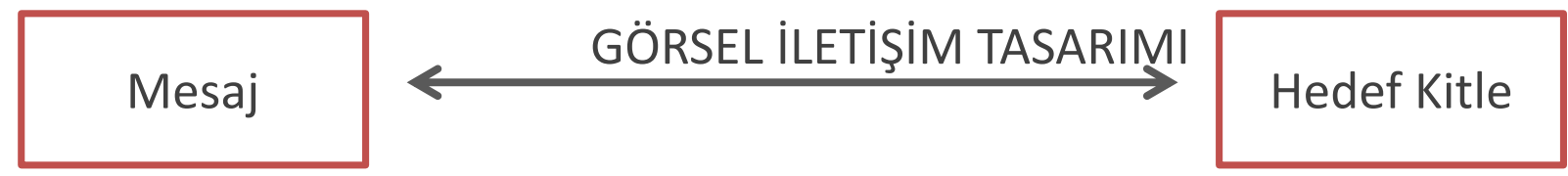

Şekil 2: Görsel iletişim tasarımı

Günümüz teknolojisinin görsel iletişimi oldukça kuvvetli şekilde etkilediği açıktır. Geleneksel ortamlar yerine artık daha çok sayısal (digital) ortamların tercih edilmesi ve insanların sayısal ortamlara gün geçtikçe daha fazla adapte olması bunun bir göstergesidir. Bu çerçevede günümüzde geleneksel ortamların yanında çok sayıda görsel iletişim uygulama alanı bulunmaktadır.

$\mathrm{Bu}$ uygulama alanları disiplinler arası bir çalışmayı gerektirecek şekilde günümüzde gerçekleştirilmektedir. Bu alanlar genel hatlarıyla reklam ve tanıtım, kurumsal kimlik çalışmaları, ambalaj tasarımı, fotoğraf, video ve animasyon, bilgilendirme tasarımı, web ve mobil uygulamalar, yazılım projeleri ve arayüz tasarımı, 3 boyutlu modelleme, multimedia uygulamaları, tüm etkileşimli sayısal uygulamalar ile oyun tasarımı projeleri olarak değerlendirilebilir. Görüldüğü üzere görsel iletişim tasarımı çalışma alanı hem güncel kullanıcı pratikleriyle hem de aşağıda açılanan oyunlaştırmanın uygulama alanıyla kuvvetli bir yakınlık göstermektedir. Günümüzde görsel tasarım alanında görsel iletişim ve oyunlaştırma uygulamaları önemli ölçüde birlikte değerlendirilerek mevcut tanımlar ve örnekler değerlendirilebilir.

\section{Oyunlaştırma}

Oyunlaştırma (gamification) terim olarak ilk kez 2002 yılında Nick Pelling tarafindan o zamanki anlamıyla elektronik işlemlerin oyun benzeri yollarla daha hızlı ve daha eğlenceli hale getirilmesi adına kullanılmıştır. ${ }^{14}$ Alanyazında kesin olarak kabul edilmiş bir tanımı henüz bulunmamasına rağmen farklı tanımlamalar açısından bakıldığında benzer özelliklere sahip olduğu da görülmektedir. $\mathrm{Bu}$ tanımlar arasında son yıllardaki oyunlaştırma çalışmalarının neredeyse tamamında yer alan tanıma göre oyunlaştırma, kullanıcı deneyimini (user experience) ve kullanıcı bağlılığını (user engagement) arttırmak amacıyla sayısal oyun unsurlarının (digital game

\footnotetext{
12 Joanna Choukeir, "İletişim tasarımı, güzel bir afişten çok daha fazlasıdır”, Grafik Sanatlar Üzerine Yazılar, Sayı: 126, 2013, http://gmk.org.tr/uploads/news/file-1458588873674562719.pdf erişim tarihi 20 Nisan 2018

${ }^{13}$ J. Frascara, C. D.: P. M. A. P.

${ }^{14}$ Nick Pelling, "The (short) prehistory of gamification", https://nanodome.wordpress.com/2011/08/09/the-shortprehistory-of-gamification/ erişim tarihi 20 Nisan 2018
} 
elements) oyun dişı alanlarda kullanımını tanımlayan bir terimdir. ${ }^{15}{ }^{16} \mathrm{Bu}$ durumda oyunlaştırmanın terim olarak oyun dünyasının geniş kapsamı içinde yer alan belirli özelliklerden şekillenerek ortaya çıktığı anlaşılmaktadır. Oyun dünyasına terminoloji açısından genel çerçevede bakıldığında game ve play ifadeleri karşımıza çıkmaktadır. Bu kavramlar köken olarak Yunanca'daki paidia ve ludus kavramlarına dayanmaktadır. ${ }^{17}$ Kavram olarak paidia (ya da playing), genellikle çocuk oyunlarında sıklıkla bulunan doğaçlama, kendiliğinden olan ifadelerin ve eğlencenin gücünü betimleyen temel kavramdır. Ludus (ya da gaming) ise kazananlar ile kaybedenleri tanımlayan ve genellikle boardgame ve video oyunlarında kendini gösteren kurallara ve rastgele seçilmiş engellere bağlı oluşan biçimsel oyun veya oynamadır. ${ }^{18} \mathrm{Bu}$ kavramalar ile oyunlaştırma ilişkisine bakıldığında oyunlaştırma, oyun tasarımı unsurlarını (game design elements) kullanan bir tasarım stratejisi veya gamefulness (gameful design) için tasarlamanın tasarım amacı olarak da tanımlanabilir. ${ }^{19}$ Buna karşılık playfulness ise aynı paidia tanımında olduğu gibi insanların gündelik, sıradan, ciddi olmayan, belirgin bir amacı ve gerçek dünya sonuçları beklentisi ile yaklaşmadıkları bir zihniyettir. ${ }^{20} \mathrm{Bu}$ bilgilerin çerçevesinde oyunlaştırma playfulness için sistematik bir tamamlayıcıdır denilebilir. ${ }^{21}$

Günümüzde oyunlaştırma çalışmalarının farklı alanlarda ele alındığı görülmektedir. Genellikle insanların bir konuya ilgisini çekerek motivasyonunu arttırmak ve katılımını sağlamak amacıyla birçok alanda oyunlardan yararlanılması düşüncesi uzun sayılabilecek bir geçmişe sahip olmasına rağmen bu ilişki çerçevesinde oyunlaştırmanın kavram olarak özellikle 2000'li yıllarla birlikte kullanılmaya başlandığ görülmektedir. ${ }^{22}$ Davranışsal ekonomiden türetildiği de düşünülen bu terim uzun bir geçmişe sahip olmamasına rağmen iş dünyasının farklı alanlarında, pazarlamada, psikolojide ve tasarım alanlarında kendine rol edinmiştir. ${ }^{23}{ }^{24}$ İş dünyasında ve pazarlama faaliyetlerinde karşımıza çıkan oyunlaştırma uygulamaları, müşteri katılımının sağlanmasıyla marka ve firma ile müşteri arasında bağların güçlendirilmesine yönelik bir araç olarak önemli firsatlar sunmaktadır. ${ }^{2526}$ Farklı alanlarda kullanımının arttı̆̆ 1 gözlenen oyunlaştırmanın insan davranışı ve motivasyonunu etkileyen güçlü ve esnek yapısı ile farklı problem çözümlerine katkıda bulunabilecek şekilde uygulanabildiği görülmektedir. ${ }^{27}$ Buna paralel olarak oyunlaştırma uygulamalarının eğitim alanında sıklıkla kullanılması kaçınılmazdır. Bunun temelinde sayısal bir çağda olduğumuz gerçeği ile milenyum neslinin en önemli eğlence araçlarından birinin sayısal oyunlar olmasıdır. ${ }^{28}$ Sayısal çağda doğup büyüyen ve bilgisayar, video oyunları ve İnternet'i ana dili gibi benimseyen nesil sayısal yerliler (digital natives) olarak adlandırılmaktadır. ${ }^{29}$ Sayısal yerlileri doğru anlamak ve onların dünyasına uygun eğitim içerikleri geliştirmek adına da oyun

\footnotetext{
${ }^{15}$ Sebastian Deterding vd., Using Game Design. Proc. The ACM CHI Conference on Human Factors in Computing System, Vancouver May1s 2011, s. 2425-2428.

${ }^{16}$ Sebastian Deterding vd., From game design elements to gamefulness: defining gamification, Proc. 15 th Int. academic MindTrek conference: Envisioning future media environments, Tempere Eylül 2011, s. 9-15

${ }^{17}$ Roger Caillois, Man, Play, and Games.(Translated by Meyer Barash, University of Illinois Press, Chicago 2001.

${ }^{18}$ Andres Lucero vd., "Playful or Gameful?: creating delightful user experiences", Interactions (ACM), Say1: 21, 2014, s. 34-39.

${ }^{19}$ S. Deterding vd., F. G. D. E. T. G.: D. G,. s. 9-15

${ }^{20}$ A. Lucero vd., P. O. G.?: C. D. U. E., s. 34-39.

${ }^{21}$ S. Deterding vd., F. G. D. E. T. G.: D. G,. s. 9-15

${ }^{22}$, Mustafa Halid Karaarslan ve Başar Altuntaş, "Türkiye'deki Seçilmiş Pazarlama Vakalarının Oyunlaştırma Kavramı Çerçevesinde İncelenmesi"” Mehmet Akif Ersoy Mehmet Akif Ersoy Üniversitesi Sosyal Bilimler Enstitüsü Dergisi, Say1: 17, 2016, s. 433-447.

${ }^{23}$ Patrick Jagoda, "Gamification and Other Forms of Play", Boundary 2, Say1: 2, 2013, s. .113-144.

${ }^{24}$ Robert Hunter, The Gamification Handbook: Everything You Need to Know about Gamification, Emereo Publishing, USA 2011.

${ }^{25}$ M. H. Karaarslan ve B. Altuntaş, T. S. P. V. O. K. Ç. İ., s. 433-447.

${ }^{26}$ Roger Conaway ve Mario Cortes Garay, "Gamification and Service Marketing", SpringerPlus, Say1:1, 2014, s. 1-11.

${ }^{27}$ Gabe Zichermann ve Christopher Cunningham, Gamification by Design Implementing Game Mechanics in Web and Mobile Apps, O'Reilly Media, Canada 2011.

${ }^{28}$ Aras Bozkurt, "Homo Ludens: Dijital oyunlar ve eğitim”, Eğitim Teknolojileri Araştırmaları Dergisi, Sayı:1, 2014, s. 0.

${ }^{29}$ Marc Prensky, “Digital Natives, Digital Immigrants”, On the Horizon, Say1: 5, 2001, s. 1-6.
} 
unsurlarının kullanılması doğal bir sonuçtur. McGonigal dijital oyun oynama alıșkanlığına sahip bir bireyin 21 yaşına kadar yaklaşık 10000 saat çevrimiçi oyun oynadığını ve bunun Amerika Birleşik Devletleri'nde yaşayan bir birey olduğu varsayıldığında aynı bireyin beşinci sınıftan lise mezuniyetine kadar aldığı toplam ders saatine yaklaşık olarak eşit olduğunu belirtmiştir. McGonigal aynı zamanda bu kadar saat vakit harcanarak herhangi bir alanda uzman olunabileceğini belirterek sayısal oyunların önümüzdeki süreçteki etkisinin önemini vurgulamıştır. ${ }^{30} \mathrm{Bu}$ bilgiler 1şığında oyun tabanlı öğrenme (game-based learning) anlayış1 önem kazanmaktadır. Oyunlar, yenilikçi bir eğitim paradigması oluşturmak için eğitime entegre edilmiştir ve oyun tabanlı ögrenme olarak bilinen bu paradigma, oyunu öğrenme içeriğini aktarmak için bir araç olarak kullanmaktadır. ${ }^{31}$ Oyun tabanlı eğitim içerikleri üzerine çalışan Jumpido firması oyun dünyasının çocukların hayal gücünü geliştirip problem çözmelerine yardımcı olduğunu ve öğrenme materyalleri açısından puanlamanın ve kazanmanın önemli olduğunu belirtmiştir ve bunun oyun tabanlı öğrenme olduğunu vurgulamıştır [Şekil 3]. ${ }^{32}$

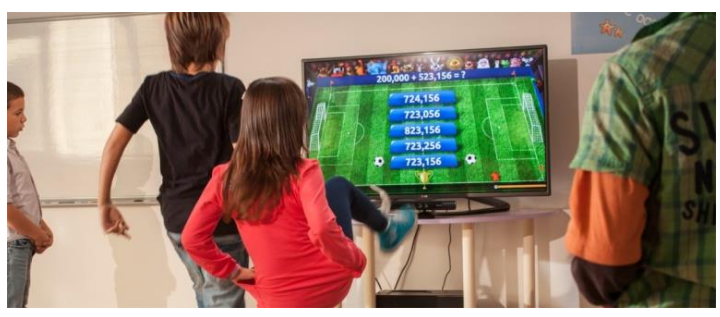

Şekil 3: Jumpido firmasına ait oyun tabanlı öğrenme örneği (http://d2wjkg2tbqmlsj.cloudfront.net/static/img/gamebased-learning-jumpido.jpg adresinden alınmıştır. Erişim tarihi 27 Nisan 2018)

Hangi alan için kullanılırsa kullanılsın oyunlaştırma uygulamalarında puan, seviye, avatar, rozet, ödül, hikaye gibi oyun dünyasının önemli bileşenlerinden faydalanılır ve bu bileşenler oyun dünyasına ait olmayan ortamlara entegre edilir. Bu amaçla kullanılmak ve oyunlaştırmayı daha iyi açıklayabilmek adına Werbach ve Hunter "FOR THE WIN How GAME THINKING Can Revolutionize Your Business" isimli çalışmalarında bir oyunlaştırma modeli geliştirmişlerdir. Bu modele göre oyunlaştırma üç ana temel üzerine kurulur: ${ }^{33}$

- Dinamikler (dynamics)

- Mekanikler (mechanics)

- Bileşenler (components)

Bu üç başlığa ait unsurlar aşağıdaki tabloda gösterilmiştir [Tablo 1]:

\begin{tabular}{|l|l|l|}
\hline OYUNLAŞTIRMA & Mekanikler (mechanics) & Bileşenler (components) \\
\hline Dinamikler (dynamics) & Zorluklar (challenges) & Başarılar (achievements) \\
\hline Sinırlamalar (constraints) & Şans (chance) & Avatarlar (avatars) \\
\hline Duygular (emotions) & Rekabet (competition) & Rozetler (badges) \\
\hline Hikaye (narrative) & İş birliği (coorperation) & Zorlu zirve noktaları (boss fights) \\
\hline İlerleme (progression) & Geri bildirim (feedback) & Koleksiyonlar (collections) \\
\hline İlişkiler (relationships) & Kaynak edinme (resource acquisition) & Savaş (combat) \\
\cline { 2 - 3 } & &
\end{tabular}

\footnotetext{
${ }^{30}$ Jane McGonigal, Reality is Broken: Why Games Make Us Better and How They Can Change the World, The Penguin Press, New York 2011.

${ }^{31}$ Phit-Huan Tan vd., Adaptive digital game based learning framework, Proc. 2nd Int. conference on digital interactive multimedia in entertainment and arts DIMEA'07, Perth Eylül 2007, s. 142-146.

32 "What is game-based learning?", http://www.jumpido.com/en/education/kinect/school/game-based-learning erişim tarihi: 16 Nisan 2018

${ }^{33}$ Kevin Werbach ve Dan Hunter, For The Win: How Game Thinking Can Revolutionize Your Business, Wharton Dijital Press, Philedelphia 2012.
} 


\begin{tabular}{|l|l|}
\hline Ödüller (rewards) & İcerik (content) \\
\hline Alışverişler (transations) & Hediye paylaşımı (gifting) \\
\hline Sıra (turns) & Lider tablosu (leaderboards) \\
\hline Kazanma durumları (win states) & Seviyeler (levels) \\
\hline \multirow{2}{*}{} & Puanlar (points) \\
\cline { 2 - 2 } & Maceralar (quests) \\
\cline { 2 - 2 } & Sosyal grafikler (social graphs) \\
\cline { 2 - 2 } & Takımlar (teams) \\
\cline { 2 - 2 } & Sanal varlıklar (virtual goods) \\
\cline { 2 - 2 } &
\end{tabular}

Tablo 1: Oyunlaştırma unsurları

Yukarıda bahsedilen modelin altı aşamada gerçekleşmesi planlanmıştır. D6 modeli olarak da bilinen bu modelin aşamaları şöyledir: ${ }^{34}$

- İş Hedeflerinin Belirlenmesi (DEFINE Business Objectivess)

- Hedeflenen Davranışların Betimlenmesi (DELINATE Target Behaviors)

- Oyuncuların tanımlanmasi (DESCRIBE Your Players)

- Aktivite döngülerinin kurgulanması (DEVISE Activity Cycles)

-Eğlence faktörü (DON'T Forget the Fun!)

- Uygun aracin belirlenmesi (DEPLOY Appropriate Tools)

\section{Görsel Tasarım ve Oyunlaştırma}

Görsel tasarım açısından bakıldığında özellikle insanların katılımını ve motivasyonunu arttırarak istenen davranış ve tutumların gerçekleştirilmesine yönelik olarak oyunlaştırma uygulamalarının kullanımı önemli ölçüde faydalı olarak gözükmektedir. Görsel tasarım prensipleri ve yaratıcı yönünün oyunlaştırmanın insanlar üzerindeki pozitif etkileri birlikte ele alınarak aşağıdaki örnekte olduğu gibi çok sayıda tasarım çözümü gerçekleştirilebilmektedir. Bu örnekte insanların çevreyi kirletmemeleri adına geliştirilmiş bir görsel tasarım uygulamasından oyunlaştırmanın kullanımı görülmektedir [Şekil 4].

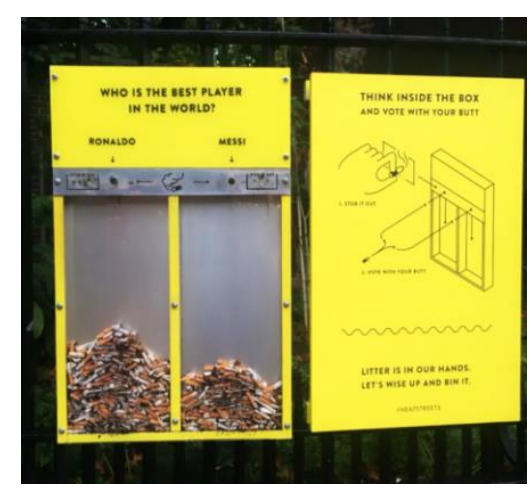

Şekil 3: Oyunlaştırma örneği (https://i.pinimg.com/736x/09/f2/aa/09f2aac1c7483efbb93029e85f0a31b2.jpg adresinden alınmıştır. Erişim tarihi 25 Nisan 2018)

Sosyal medya kullanım pratikleri ile oyunlaştırmanın mobil ve web uygulamaları üzerinde birlikte kullanımı da son yıllarda oldukça popülerdir. En bilinen örneklerden başta Foursquare, Tripadvisor ve Yemeksepeti gibi birçok benzer uygulama kullanıcı açısından ödül,

${ }^{34}$ K. Werbach ve D. Hunter, F. T. W.: H. G. T. C. R. Y. B. 
derecelendirme, paylaşım, avatar, rozet, rekabet gibi oyunlaştırmanın temel niteliklerini kullanarak tasarlanmaktadır. Bahsedilen bu örnekler daha çok e-ticaret ve sosyal medya platformlarına yönelik olarak tasarlanmıştır ve benzer çok sayıda örmeğe rastlamak mümkündür. Bunların yanında dil öğretimini oyunlaştırarak eğlenceli hale getiren Duolingo veya spor yapmayı oyunlaştırarak sosyal bir yapı içinde rekabet ortamı yaratan Nike+ uygulamaları da oyunlaştırmaya oldukça iyi örneklerdir [Şekil 5 ve 6].

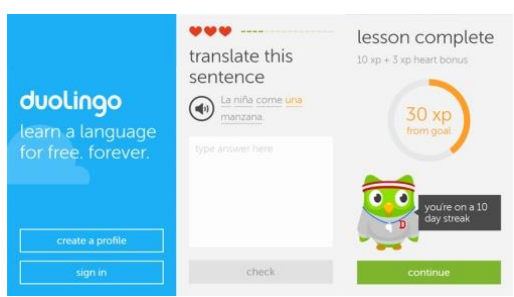

Şekil 5: Duolingo (https://winblogs.azureedge.net/devices/2014/11/DUPLINGO.jpg adresinden alınmıştır. Erişim tarihi 26 Nisan 2018)

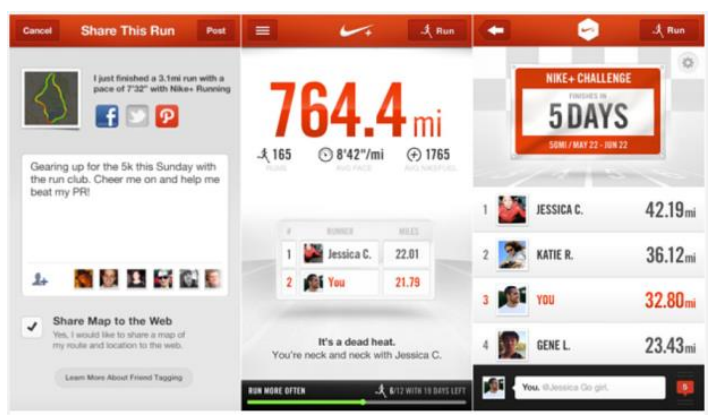

Şekil 6: Nike+ (https://9to5mac.files.wordpress.com/2013/07/nike.png?w=1500\&h=1000 adresinden alınmıştır. Erişim tarihi 26 Nisan 2018)

Yukarıda gösterilen örnekleri arttırmak mümkündür ve satıs faaliyetlerinden eğitime, sosyal medyadan kamusal uygulamalara kadar çok sayıda farklı alanda kullanılmış oyunlaştırma çalışmasına rastlamak mümkündür. Son günlerde çeşitli kaynaklarda sıklıkla bahsedilen Çin yönetimi tarafından Zhima (Sesame) Credit adı verilen bir sosyal kredi sistemi kurulması ve belirli bir bölgede denenmeye başlanması oyunlaștırmanın en gelișmiș örneklerinden biri olarak kabul edilebilir. 2020 yılında ülke genelinde uygulamaya konulması planlanan bu sistemin oyunlaştırmayı vatandaşlığın merkezine yerleştirerek vatandaşlık kavramını fizikselden dijitale geçirmeyi amaçlaması üzerine kuruludur [Şekil 7]. ${ }^{35}$

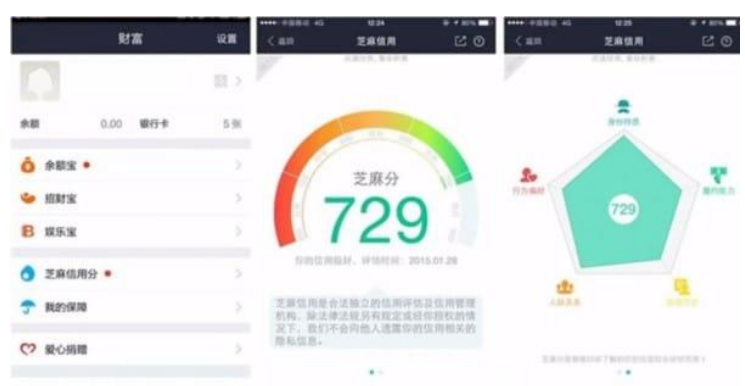

Şekil 7: Zhima (Sesame) Credit (https://sherpa.blog/wp-content/uploads/2017/01/ccp-600x311.jpg adresinden alınmıştır. Erişim tarihi 21 Nisan 2018)

\footnotetext{
${ }^{35}$ Berk Bayri, “Sosyal kredi: Oyunlaştırmanın karanlık yüzü”, https://sherpa.blog/sosyal-kredi-oyunlastirmaninkaranlik-yuzu erişim tarihi: 21 Nisan 2018
} 


\section{Sonuç}

Görsel tasarım uygulamaları açısından bakıldığında oyunlaştırmanın kullanımı oldukça pozitif etkilere sahiptir. Oyunlaştırma, oyunsal düşünme mantığı içinde oyun mekaniklerinin problem çözme ve bağlılık duygusu sağlama amaçlarıyla deneyimlerin oyuna çevirmesi gibidir. ${ }^{36}$ Görsel tasarım bakış açısıyla insanların farklı alanlardaki deneyimlerine yönelik tasarımlar yapmak ve bu tasarımların yaratıcı süreçler sonunda farklı, katılımı arttırıcı, motive edici ve devamlılığ sağlayan araçlarla uygulanması önemli bir yere sahiptir. İzlenecek yollardan ve kullanılacak araçlardan birinin oyunlaştırma olması bu çalışmada bahsedilen pek çok faktörü görsel tasarım uygulamaları açısından olumlu olarak etkilediği görülmektedir. Bu bilgileri desteklemesi açısından oyunlaştırmanın ikna edici teknoloji bağlamında ele alınabilecek bir tasarım dili olduğu da ifade edilebilir. ${ }^{37}$

Genel hatlarıyla bakıldığında oyunlaştırmanın görsel tasarım uygulamalarına katkıları aşağıdaki şekilde sıralanabilir:

Motivasyon: Sağladığı pozitif motivasyon ile katılımı arttırarak arttırır ve insanlara bir rol kazandırır. Böylece devamlılığg sağlayarak insanlara etkin olduğunu hissettirir.

Bağl1lık: Kullanıcı veya müşterilerin sürekli eylemleri ve bu eylemlere karşılık aldıkları geri dönüşler sebebiyle firma / marka ile aralarındaki bağlılığı güçlendirir.

Rekabet: Daha çok firmalar için geçerli olan rekabet ortamını, o firmaların oyunlaştırma uygulamalarına dahil olan kullanıcı ve müşterileri için de yarışma ortamı ve başarı hissi sağlar.

Sosyalleșme: Günümüzün en güçlü getirilerinden olan sosyalleşme ve etkileşim ortamının kurulmasını güçlendirir.

Dinamizm: Firmaların müşterilerinde ve kullanıcılarına statik ve edilgen uygulamalardan dinamik ve etken uygulamalara geçmelerine sağlayacak ortamları hazırlar.

Yenilikçi Tasarım Anlayıșı: Güncel trend ve teknoloji kullanımını teşvik ederek yenilikçi tasarım anlayışını destekler.

Farklılaşma: Alışılagelmiş faaliyetleri tercih eden rakiplerden ayrılarak yeni pazarlama, tanıtım ve reklam çözümleri sunar. Farklılaşmayı sağlayarak özgün konumlandırmaya destek sağlar

Eğlence: Belki de en önemli getirisi olan ve oyunların vazgeçilmezi eğlence unsurunu tasarım çözümleri ile bütünleştirir ve müş̧eriler ile kullanıcıların gerçekleştirecekleri eylemlere eğlence unsurunu katar.

Oyunlaştırma, kullanıcıları ve müşterileri birçok yönde etkilemeye ve yönlendirmeye katkıda bulunmaktadır. Farklı örneklerle açıklandığı üzere insanlar özellikle yüksek motivasyona sahip, sosyal iletişim olanakları içinde rekabete dayalı, farklı ve eğlenceli aksiyonlarda rol almaya daha istekli gözükmektedirler. Bu tutum ve davranışları kuvvetli şekilde etkileyecek özellikleri sahip oyun kavramından yola çıkan oyunlaştırmanın farklı çözüm seçenekleriyle güncel tasarım uygulamalarında kullanılması doğal bir sonuçtur. Günümüzde yeni bir paradigma olarak güncel tasarım uygulamalarında yaygınlaşan oyunlaştırma kavramının gelecekte daha fazla alanı ve sektörü de kapsayarak kullanımının artması öngörülmektedir.

\footnotetext{
${ }^{36}$ G. Zichermann ve C. Cunningham, G. D. I. G. M. W. A:M. A.

${ }^{37}$ Jon Froehlich, Gamifying Green: Gamification and Environmental Sustainability. In The Gameful World, MIT Press, Cambridge 2014, s. 563-596.
} 


\section{Kaynakça}

Merriam - Webster Sözlüğü, http://www.merriam - webster.com/dictionary/design, erişim tarihi: 17.05.2018.

TDK (Türk Dil Kurumu) Güncel Türkçe Sözlük, http://www.tdk.org.tr erişim tarihi: 17.05.2018.

Mozota, Brigitte Borja De, Tasarım Yönetimi, Mediacat Kitapları, İstanbul 2005, s. 8.

Hasdoğan, Gülay, Tasarım Kavramının Hukuktaki Gelisimi ve Endüstriyel Tasarımların Korunmasına İlişkin Ülkemizdeki Yasal Düzenlemelere Yansımaları, Tasarımda Evrenselleşme - 2. Ulusal Tasarım Kongresi Tasarım Kitabı, İstanbul 13-16 Mart 1996, s. 24.

Devrim, Özlem, "Tasarım Kavramı Üzerine Bir Deneme”, https://trendyazilari.blogspot.com/2002/10/tasarim-kavrami-uzerine-bir-deneme.html erişim tarihi: 16.05.2018.

Fontana, David, The Secret Language of Symbols, Chronicle Books, San Francisco 1994.

Künüçen, Hale ve Olguntürk, Kağan, Görsel İletişim Öğelerinin Yeni Bir Medya Dili Olarak Sinemada Yeniden Tasarım1, Proc. Int. Conference on Communication, Media, Technology and Design, , İstanbul Nisan 2014, s. 334-337.

Yaban, Nesli Tuğban, Sanat ve Görsel İletişimin Buluşma Noktasi: Ekslibris, Proc. Int. Participated Science and Culture Symposium, Batman Nisan 2012, s. 973-984.

İnanç Uyan Dur, Banu, "Türk Görsel İletişim Tasarımı Ve Kültürel Değerlerle Bağları", Uluslararası Sosyal Araştırmalar Dergisi, Sayı:37, 2015, s. 443-453.

Frascara, Jorge, Communication Design: Principles, Methods, and Practice, AllworthPress, New York 2004.

Choukeir, Joanna, "İletişim tasarımı, güzel bir afişten çok daha fazlasıdır", Grafik Sanatlar Üzerine Yazılar, Sayl: 126, 2013, http://gmk.org.tr/uploads/news/file1458588873674562719.pdf erişim tarihi 20 Nisan 2018

Pelling, Nick, "The (short) prehistory of gamification", https://nanodome.wordpress.com/2011/08/09/the-short-prehistory-of-gamification/ erişim tarihi 20 Nisan 2018

Deterding, Sebastian vd., Using Game Design. Proc. The ACM CHI Conference on Human Factors in Computing System, Vancouver Mayis 2011, s. 2425-2428.

Deterding, Sebastian vd., From game design elements to gamefulness: defining gamification, Proc. 15th Int. academic MindTrek conference: Envisioning future media environments, Tempere Eylül 2011, s. 9-15

Caillois, Roger, Man, Play, and Games.(Translated by Meyer Barash, University of Illinois Press, Chicago 2001.

Lucero, Andres vd., "Playful or Gameful?: creating delightful user experiences", Interactions (ACM), Say1: 21, 2014, s. 34-39.

Karaarslan, Mustafa Halid ve Altuntaş, Başar, "Türkiye'deki Seçilmiş Pazarlama Vakalarının Oyunlaştırma Kavramı Çerçevesinde İncelenmesi"' Mehmet Akif Ersoy Mehmet Akif Ersoy Üniversitesi Sosyal Bilimler Enstitüsü Dergisi, Say1: 17, 2016, s. 433-447.

Jagoda, Patrick, "Gamification and Other Forms of Play”, Boundary 2, Say1: 2, 2013, s. .113-144.

Hunter, Robert, The Gamification Handbook: Everything You Need to Know about Gamification, Emereo Publishing, USA 2011. 
Conaway, Roger ve Garay, Mario Cortes, "Gamification and Service Marketing”, SpringerPlus, Say1:1, 2014, s. 1-11.

Zichermann, Gabe ve Cunningham, Christopher, Gamification by Design Implementing Game Mechanics in Web and Mobile Apps, O'Reilly Media, Canada 2011.

Bozkurt, Aras, "Homo Ludens: Dijital oyunlar ve eğitim", Eğitim Teknolojileri Araştırmaları Dergisi, Sayl:1, 2014, s. 0.

Prensky, Marc, "Digital Natives, Digital Immigrants", On the Horizon, Sayı: 5, 2001, s. 1-6.

McGonigal, Jane, Reality is Broken: Why Games Make Us Better and How They Can Change the World, The Penguin Press, New York 2011.

Tan, Phit-Huan vd., Adaptive digital game based learning framework, Proc. 2nd Int. conference on digital interactive multimedia in entertainment and arts DIMEA'07, Perth Eylül 2007, s. 142 146.

"What is game-based learning?", http:/www.jumpido.com/en/education/kinect/school/gamebased-learning erişim tarihi: 16 Nisan 2018

Werbach, Kevin ve Hunter, Dan, For The Win: How Game Thinking Can Revolutionize Your Business, Wharton Dijital Press, Philedelphia 2012.

Bayri, Berk "Sosyal kredi: Oyunlaştırmanın karanlık yüzü”, https://sherpa.blog/sosyal-kredioyunlastirmanin-karanlik-yuzu erişim tarihi: 21 Nisan 2018

Froehlich, Jon , Gamifying Green: Gamification and Environmental Sustainability. In The Gameful World, MIT Press, Cambridge 2014, s. 563-596. 